\title{
What is in It for Me? Identifying Drivers of Blockchain Acceptance among German Consumers
}

Florian O. Knauer, Andreas Mann

Chair of Marketing, University of Kassel, Germany

Correspondence: knauer@wirtschaft.uni-kassel.de

Received: 17 July 2019 Accepted: 11 September 2019 Published: 8 October 2019

\begin{abstract}
From a consumers' perspective, Blockchain Technology (BCT) holds the potential to decrease transaction costs, improve privacy and redesign social interactions, which potentially leads to enhanced consumer power in transactional relationships. Nevertheless, only a few consumers use Blockchain-based applications consciously. By combining earlier research about BCT acceptance with different conceptualisations in the technology acceptance field (i.e. the Technology Acceptance Model and Rogers' Diffusion Theory), a Blockchain-specific model to explain the usage intention has been developed and validated by conducting an online survey among 157 German consumers. While most of them have recognised the technology's existence and confirmed its general relevance, many consumers do not know how to access and profit from BCT. Integrating the results of a Structural Equation Model and Pairwise Comparisons between typical attributes of Blockchain-based applications, specific beliefs about BCT usage are found to have a remarkable impact on consumers' acceptance. Based on the results, strategies to promote the acceptance of BCT among consumers are discussed from a marketer's, developer's and researcher's point of view.
\end{abstract}

Keywords: Blockchain, Distributed Ledger Technology, Technology Acceptance, Technology Diffusion, Consumer, Germany

\section{Introduction}

More than ten years after Satoshi Nakamoto (pseudonym) released his famous white paper [1] leading the way for the Bitcoin Blockchain and several follow-up applications based on distributed ledgers, the technology ${ }^{\mathrm{i}}$ has recently been recognised by the "business world" and is in ongoing exploitation [2]. However, only about $4 \%$ of consumers are already using Blockchain technology (BCT) consciously [3].ii This is particularly surprising, because consumers could already profit from a wide range of Blockchain based applications ${ }^{\text {iii }}$ in terms of improvements in security, availability of applications or cost reductions and thereby increase their independence from banks, technology groups or individual states $[4,5,6]$. Furthermore, it is often advocated that BCT could reinforce consumers' data sovereignty by allowing them to share their data anonymously or for specific purposes only [7]. Beyond these specific functionalities, BCT offers consumers new opportunities to select favourable social systems for their interaction with others by "configuring" or choosing Blockchain-based solutions on the basis of their preferred set of assets, rules, norms or social coordination mechanisms [for this and below: 8]. In consequence, the technology probably changes economical structure not only by lowering transactio costs, but by lowering transaction costs, but by enforcing rules based on algorithms that are only partly asserted by trustworthy institutions so far and thereby constitutes new ways to build consensus (e.g. about what is of value) in the digital space. Concretely, BCT might enable consumers to take more active positions in transactions (e.g. by selecting "smart contracts") [6] or to foster their influence on prices and conditions on many markets due to increased market transparency [9].

The question now is why despite this potential the majority of consumers still hesitates to use Blockchain-based applications: maybe they are not aware of the technology's properties, perceive a lack of well-designed applications or are wellinformed, but not convinced by the technology. Anyhow, when aiming at pushing the diffusion of Blockchain-based applications, it is essential to identify the reasons for consumers' current lack of acceptance concerning the underlying technology, especially because it is expected to strongly affect developers' risk of market introduction [10].

To do so, it is worth defining what is actually meant by "acceptance": starting at verbal definitions of the term, it refers 
to an attitudinal degree of affirmation regarding an object, e.g. a technology [11]. Nevertheless, the construct is often measured by actual usage or adoption, which is a possible, but not an inevitable consequence ${ }^{\text {iv }}$ of a positive attitude towards usage that typically constitutes the intention to use a technology [12]. Anyhow, a usage intention, which we consider as "acceptance" in this paper in accordance with common acceptance theories and models, ${ }^{\mathrm{V}}$ can be regarded as a preliminary step for actual usage [13]. Therefore, it is very important to understand the attitudinal dimensions that drive the intention to use BCT, which will be the focus of this paper. In particular, it targets at identifying perceptions of BCT that are critical for its acceptance by consumers and further analyses their quantitative influence on usage intention to derive strategies for enhancing acceptance.

After discussing earlier publications that deal with acceptance aspects in the Blockchain field (part 2), common theories and models addressing technology acceptance are integrated and combined with Blockchain-specific beliefs into a novel research model that aims at explaining the acceptance of BCT among consumers (part 3). The methodology to empirically check the model's validity is presented in part 4. Therefore, an online survey among 157 German participants was conducted to test the research model. Survey's results are described in part 5. Conclusions are drawn and reflected in part 6.

\section{Acceptance Research in the Blockchain Field}

Different surveys from 2015-2018 report that about 50\% of all consumers are aware of Bitcoin [4, 14, 15] and about 30\% of BCT [3, 15]. In consequence, a lack of awareness does not explain low adoption rates. Henry et al. [14] further investigated the knowledge of central BCT characteristics among USAmericans in 2017, which was very low and thus might be critical for further adoption.

Qualitatively, Folkinshteyn and Lennon [for this and below: 17] combine case studies and an interview with a Blockchain expert (Lasha Antadze) for identifying acceptance determinants of the Bitcoin and the Blockchain technology used as a financial software platform from developers' and end users' perspective. Their analysis results in a roughly structured accumulation of (potential) acceptance drivers. Baur et al. [18] follow a comparable approach by interpreting interviews with consumers and professionals to find usage determinants of cryptocurrencies, but furthermore assess the current state of perception concerning common acceptance determinants, in particular with regard to the Bitcoin. Woodside et al. [for this and below: 19] discuss BCT's status of adoption among firms from a management perspective by combining secondary data. For the purpose of this paper, in particular their discussion of drivers (e.g. transparency, costs, user control) and drawbacks (e.g. regulatory status, privacy and security) of BCT's adoption is addressed in addition to consumer-focused investigations, whereby it should be noted that adoption motives of firms probably differ from consumers' ones. On the level of applications, Francisco and Swanson [20] develop a conceptual model to explain the use of Blockchain-based Supply Chains that particularly puts a spot on the relevance of a system's transparency.

Quantitatively, Queiroz and Fosso Wamba [for this and below: 21] consider the level of transparency as a direct determinant of the intention to adopt BCT among US-American and Indian Supply Chain professionals. Surprisingly, their survey does not reveal a significant effect of the transparency on the usage intention and only partly confirms the relevance of some common acceptance constructs (in particular of "Facilitating conditions" and "Social influence") as well as of the trust among the stakeholders of a Blockchain for the adoption intention. Authors provide low awareness of BCT and cultural differences as possible explanations for their results. Abramova and Böhme [for this and below: 4] estimate a Structural Equation Model to explain Bitcoin usage of consumers. In particular, they specify risks and carve out the level of decentralisation, perceived security and control as well as characteristics regarding transaction processing as Blockchain-specific acceptance determinants. However, it remains open to discussion if these beliefs are also relevant for the acceptance of the underlying BCT and which additional perceptions might be crucial in this context. Kumpajaya and Dhewanto [22] further empirically validate a more generic model explaining Bitcoin-usage in Indonesia that explicitly incorporates "knowledge" as relevant acceptance predictor.

To sum it up, most of the few publications addressing Blockchain acceptance among consumers identify and structure (potential) acceptance drivers, but forego the empirical examination of their actual effect on usage (intention) or predominantly focus single applications only, in particular the Bitcoin Blockchain or Supply Chain solutions. This paper helps to close the resulting research gap by developing and empirically testing an acceptance model on BCT layer. Some of the earlier publications thereby serve to identify Blockchain-specific beliefs that are expected to influence consumers' usage 


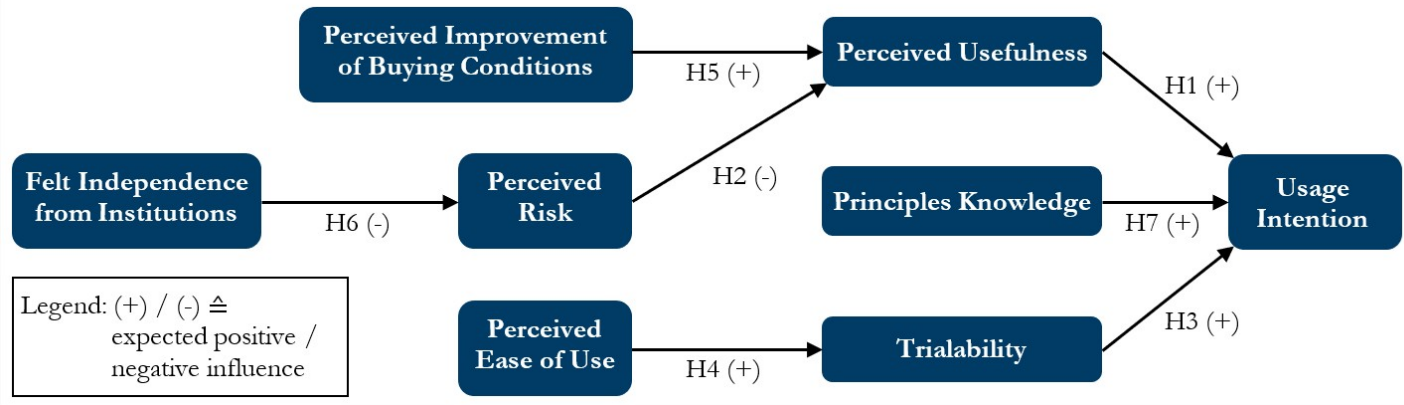

Figure 1. Research Model.

intention. These beliefs are either incorporated by specifying more generic beliefs for a BCT context (cf. Table 1; all tables in the appendix) or represent newly developed Blockchain-specific variables in the research model (cf. Table 2).

\section{Conceptual Framework and Research Model}

This part is concerned with deriving the research model and its hypothesis, displayed in Figure 1. At the basic level, the research model is grounded on the "Theory of Reasoned Action" (TRA) developed by Martin Fishbein. The theory offers an empirically confirmed [23] framework for explaining the execution of behaviours that can be considered as a result of predominantly cognitive consideration $^{\mathrm{vi}}$ and thus appears to be suitable for the initial or enduring usage of BCT due to the appreciable consequences and efforts technology changes imply [24].

The TRA distinguishes different types of beliefs to be crucial for forming a behavioural intention: "Behavioural Beliefs" are defined as the perceived probability that a behaviour (e.g. technology usage) leads to a specific outcome, e.g. privacy [for this and below: 13]. By forming Behavioural Beliefs, an overall "Attitude Toward the Behaviour" (ATB) is formed spontaneously. In addition to ATB, the TRA incorporates "Normative Beliefs", referring to the extent that others appreciate a behaviour or are likely to perform it, as influencing factor. Although Blockchain-based applications are "social" by design, these beliefs are not considered in the following, because most consumers are not expected to know many reference persons already using BCT or to feel social pressure to do so [20]. The "Theory of Planned Behaviour", an extension of TRA, further adds "Control Beliefs", which describe the felt control over performing a behaviour that might be restricted by factual or perceived barriers (e.g. lacking confidence). But due to many freely accessible Blockchain based applications, factual barriers should not be of notable relevance for BCT and perceived barriers will be captured by another variable ("Trialability", details later) to some extent.

Based on TRA, Davis specified Behavioural Beliefs determining the usage of technological innovations and integrated them into the "Technology Acceptance Model" (TAM) [25, 26], which has already been validated in a Blockchain context [22]. According to the TAM, one can assume that the "Perceived Usefulness" (PU), defined here as "the perceived likelihood that the technology will benefit the person in performance of some task" [26, p. 1063], has a direct positive influence on the usage intention of BCT:

H1: Perceived Usefulness positively influences the intention to use Blockchain technology

It is noteworthy that PU should be considered relative to other technologies, because individuals continuously compare the functional benefits of currently used technology to technological alternatives [27]. The same holds for "Perceived Ease of Use" (PEOU), capturing expected mental and physical efforts necessary to learn and use a technology that lead to a general perception of a technology's "simplicity" [25, 26, 27] PEOU is especially relevant for the initial use of a technology and therefore, due to the low percentage of actual BCT users, expected to have a remarkable impact on overall acceptance of BCT [26]. Inside the TAM, it has a direct as well as an indirect positive effect on usage intention mediated by PU [28], but will be incorporated into the research model otherwise (cf. H4).

Over time, several modifications of the TAM emerged: Pavlou in particular added "Perceived Risk" (PR), defined as "consumer's subjective belief of suffering a loss in pursuit of a desired outcome" [29, p. 77], which has a direct negative impact on the intention to force an online transaction [for this and below: 29]. This "outcome" can refer to costs, performance, security or privacy. Following Pavlou, PR is particularly 
important in the context of online transactions due to the impersonality, the limited possibilities to check the quality of goods and services in advance and potential interventions by third parties and thus appears to be indispensable in a BCT context. Because the reduction of risks in a transactional context is an essential idea of BCT constituting its usefulness [30], PR probably should be interpreted as a determinant of PU:

H2: Perceived Risk negatively influences Perceived Usefulness

Because of its confirmed validity for strongly differing applications (for meta-analysis, see [31]), the TAM is considered to be an appropriate model for gathering general information about perceptions associated with or for figuring out a general level of satisfaction regarding a technology [for this and below: 32]. However, whenever aiming at collecting information about specific perceptions that promote or impede a technology's acceptance, the quite generic TAM should be combined with other conceptualisations that allow a theory-based enrichment with context-specific constructs. To do so, further beliefs are derived in the following.

Firstly, "Trialability" is introduced, referring to the (perceived) extent to which possibilities to experiment with an innovation are available [33]. Thus, it can be considered as expression of a Control Belief inside the TRA [34]. ${ }^{\text {vii }}$ The variable is included, because it is especially important at early stages of diffusion, which is the case if only a few, very "innovative" consumers are using an innovation [33, 34]. As introductorily mentioned, this holds for BCT. The variable stems from the so-called "Diffusion Theory" by Rogers [for this and below: 33]. In contrast to the TAM, it explicitly models the dynamic process of technology adoption every individual passes through as part of a social system, before, while and after adopting a (technological) innovation [34], thus allowing acceptance determinants viii to vary in importance over time. According to Rogers, Trialability fosters adoption (respectively usage):

H3: Trialability positively influences the intention to use Blockchain technology

Trialability is furthermore used as a "bridge" to incorporate PEOU into the research model: the easier learning and using of a technology is perceived, the easier it is to try and the more likely consumers are expected to confidently state that they know possibilities to initially use it, i.e. expressing a higher Trialability [33]:
H4: Perceived Ease of Use positively influences Trialability

All theory-based beliefs discussed correspond to more specific beliefs in the context of Blockchain-based applications, which are repeatedly mentioned in earlier Blockchain-related research and called "subordinate beliefs" in Table 1. The perception of these subordinate beliefs is strongly related to actual (technical) characteristics of Blockchain-based applications. Table 1 schedules some of these relations that make clear how important certain (technical) properties are for the formation of certain beliefs and thus that perceptions cannot be detached from technical specifications and vice versa. In the following, Blockchain-specific Behavioural Beliefs in the sense of TRA are introduced that are constituted by typical characteristics of Blockchain-based applications (cf. Table 2).

Stemming from increased efficiency [4] and the introductorily mentioned possible enhancement of consumers' position in many markets, BCT might improve their buying conditions in the internet (including price, terms of delivery/return, etc.). Because these improvements are not expected for all applications, the variable is not incorporated in PU. However, the more consumers believe that BCT provides improved outcome, the higher PU should be:

H5: Perceived Improvement of Buying Conditions positively influences Perceived Usefulness

Felt Independence from Institutions is designed to capture a consumer's perceived ability to take decisions independent from the influence of existing institutions [35] ${ }^{\mathrm{ix}}$. This independence is potentially empowered by BCT use, because peer-to-peer transactions become possible without any bank involved $[4,17]$, centrally offered services of technology groups (e.g. search engines) are challenged by Blockchain-based solutions [36] and if participants, respectively servers, of a Blockchain are widely distributed over multiple states, their consensus is beyond the control of single states [4, 17]. This independence is not only part of the ideology many Blockchainbased solutions (e.g. the Bitcoin system) are based on [37]. It can also be considered from a risk perspective: because dependency gives institutions the possibility to intervene or to exploit consumers' vulnerability, it entails uncertainty and perceived risks [29]. H6 follows:

H6: Felt Independence from Institutions reduces the Perceived Risk 
Besides beliefs, earlier Blockchain-related research extracted a lack of actual knowledge of the technology as acceptance predictor [22]. This evidence is supported by the TRA considering knowledge as "background factor" [13]. The Diffusion Theory even describes an "Awareness stage" that is critical for the decision to even form an attitude towards a technology later on [for this and below: 33]. In this stage, having heard of an innovation, individuals seek for further information about it if they realise a potential need satisfaction by using it. Thereby, consumers acquire different types of knowledge: while "How-to-Knowledge" (HTK) refers to ways an innovation can be used, "Principles Knowledge" (PRK) is about underlying functional principles. This differentiation can be applied to BCT: beyond knowing how to come in touch with the technology, which is strongly addicted to Trialability, HTK should, in a BCT context, predominantly be about coming along with interfaces, which is widely captured by PEOU. But the functional principles (decentralisation, etc.) of BCT are not just background information, because their understanding can be regarded as necessary to understand the technology's potential to satisfy needs and to reason its existence. Thus, PRK is explicitly considered as direct antecedent of the usage intention, leading to:

H7: The level of Principles Knowledge positively influences the intention to use Blockchain technology

\section{Methodology}

To validate the research model, an online survey was conducted in July 2018. A link was sent to e-mail distribution lists of student organisations as well as sport clubs and was distributed on Social Media (convenience sample). Due to the chosen channels, participants were relatively young (in average 33 years old) measured against the German population. ${ }^{x}$ The survey was named "future technologies in everyday life" to avoid selfselection, i.e. that mainly people who are interested in BCT participate in the survey and thus bias in particular the awareness and knowledge measurement.

The survey is structured as follows (cf. Table 3): after some general questions concerning the use, intention to use and perceived relevance of BCT and selected reference technologies ${ }^{\mathrm{xi}}$, the participants were asked to state, how clearly they know the functional principles of BCT. Only participants who expressed a vague understanding of the technology's functioning were exposed to questions measuring general beliefs regarding the BCT and a "relatively clear" perceived understanding was required to reveal specific beliefs. This adaptive design was chosen, because those claiming not to have any understanding of the technology will presumably not be able to state stable beliefs about BCT and thus were asked to rate attributes of a new app for automatic online shopping that are typical for many Blockchain-based applications (e.g. Protection against subsequent manipulations) instead. For each pair of attributes participants needed to decide which is more important for them (full profile measurement). By applying a Bradley-Terry-Luce-Test [38, 39], the relative importance of these attributes was analysed. In consequence, the research model was tested directly by Structural Equation Modeling and indirectly by considering the Pairwise Comparisons.

The latent variables of the Structural Equation Model (SEM) are designed by applying the C-OAR-SE procedure for scale development [40]. In consequence, the variables "Usage Intention", "Trialability" and "Perceived Improvement of Buying Conditions" are classified as concrete attributes leading to a single-item-measure. All other constructs besides PEOU and PRK are formed by beliefs regarding the BCT. Thereby, technology's characteristics serve to reason subordinate beliefs and thus specify the formative measurement of theory-based constructs (cf. Table 1). In contrast, PEOU, although also affected by the technology's characteristics, usually is not formed by different, widely independent attributes, but more of general disposition reflected in multiple, highly correlated beliefs and therefore measured in a reflective manner. Because specific beliefs regarding the BCT and its applications are supposed to be perceived relative to the status quo, these are measured "compared to existing IT applications" (cf. Table 7). In consequence of the adaptive survey design, only 32 participants expressed these specific beliefs, which still is a sufficient number to get meaningful results for the SEM [41].

In general, constructs were measured relying on validated scales, if possible (see Table 4 for details), and backward-translation was executed for the survey's presentation inside this paper. To calculate the SEM, path-based weighting is used and a Bootstrapping including 5000 random subsamples performed using the software "Smart PLS". Thereby, actual users are assumed to also have an intention to use BCT.

Finally, to motivate the presumably already exhausted participants to reveal their knowledge of BCT, "Gamification" elements have been integrated [42] in form of a "BlockchainQuiz" consisting of ten true/false questions whereby the first five have been designed to measure How-to-Knowledge and 
the other five for measuring Principles Knowledge (for details, see Table 5). The questions have been designed to capture Blockchain-based applications most commonly used by consumers (and thus have a focus on public (permissionless) Blockchains) and to be as easy to understand while maintaining as much precision as possible. To further differentiate the participants' knowledge, they were asked to state their confidence for every answer to calculate "Confidence Ratings" that weight correct answers with strong confidence higher than correct answers with low confidence. Incorrect answers are handled contrariwise. This approach is especially used to calculate a Principles Knowledge Score for each participant which is called "Principles Knowledge" in the following.

Therefore, the calculation scheme by Hassmen and Hunt [43] is used. Due to the fact that the quiz has been designed as an appendix after the primary survey, results should be generalised carefully with respect to average knowledge levels (presumably they are overestimated), because the decision to take part in the quiz might actually be a knowledge predictor [14]. But to distinguish between participants having comparably high and low knowledge levels, which is the main purpose of the quiz, this is not a problem.

\section{Results}

5.1. Descriptive Statistics on Usage, Knowledge and Perception of the Blockchain Technology

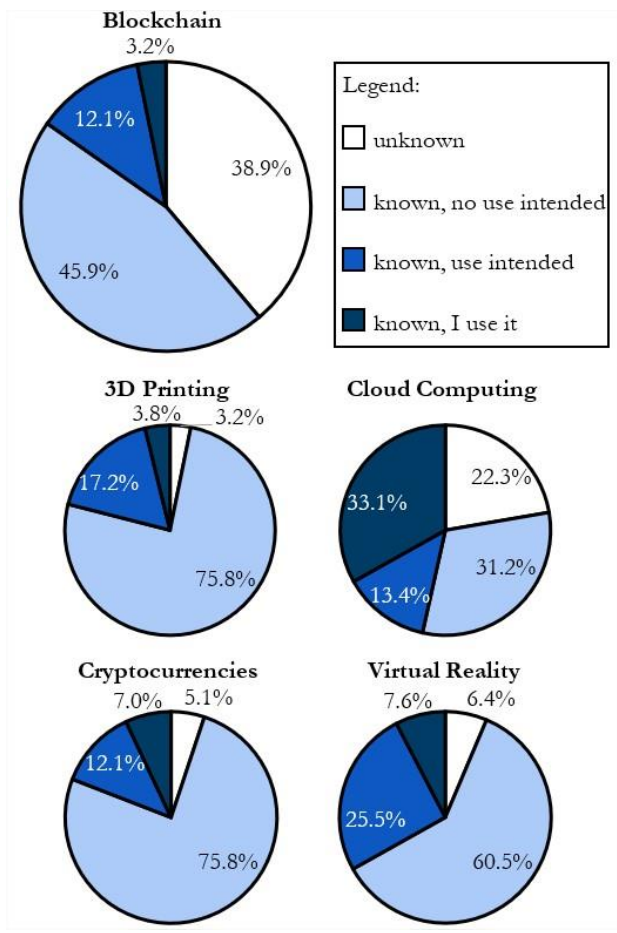

Figure 2 : Awareness and usage of selected technologies.
Looking at Figure 2, a majority of $61.1 \%$ has already heard of $\mathrm{BCT}$, which is the lowest percentage of all tested technologies, but higher than earlier surveys [3,16] indicated. Comparatively high awareness might be a consequence of the relatively young and educated participants ${ }^{x i i}$ or technology's high media coverage prior to the survey [30]. Nevertheless, only five $(3.2 \%)$ respondents state to use $\mathrm{BCT}$ and $19(12.1 \%)$ more to have the intention to do so in the future. ${ }^{\text {xiii }}$

As discussed earlier, limited knowledge might be an adoption barrier. Results of the Blockchain Quiz, displayed in Table 5, reveal that only $59 \%$ of all true/false-questions are answered correctly. In total, HTK seems to be very low, it is even not possible to show that in average, the amount of correct answers (2.55 of 5$)$ is different from random guessing ( $p>0.1$ (t-test)). Regarding PRK, 3.36 of 5 answers are correct, which is definitively a higher number than expected by random guessing ( $\mathrm{p}<0.01$ (t-test)), but also capable of improvement.

Asking for associations to the stimulus "Blockchain" (cf. Figure 3) many of the 61 participants who entered an answer think of cryptocurrencies $(n=9)$ or Bitcoin in particular ( $\mathrm{n}=14)$ or refer to essential ideas of BCT like "Decentralisation" ( $\mathrm{n}=11$ ) or "Linkage/chaining of data" $(\mathrm{n}=7)$. Also noteworthy is the repeated mentioning of the high energy consumption ( $\mathrm{n}=5$ ).

Referring to the general perception of BCT, participants think that it is generally useful, but are not convinced that it delivers value to them personally (cf. Table 6, items 1 and 2). Generally, the technology is perceived as complex and hard to understand, leading to a low PEOU. A notable risk perception can be observed, which however is not extraordinarily high. Trialability is basically very low, but perceived very differently as the high

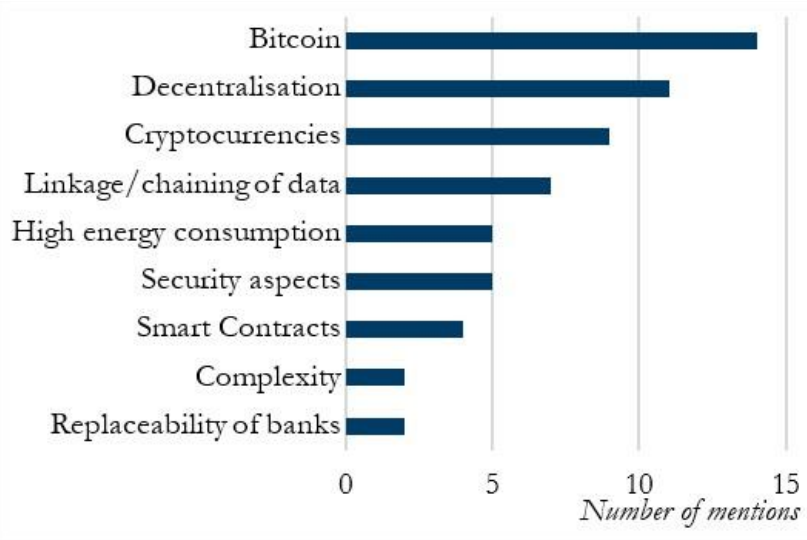

Figure 3. Associations to the stimulus "Blockchain". 
variance indicates. As anticipated, social norms currently are negligible.

Regarding specific beliefs (cf. Table 7), the answers' general proximity to the scale centre indicates that participants evaluate specific attributes of Blockchain-based applications similar to those of currently used IT applications. This holds in particular for the independence from technology groups as well as for perceived transaction costs and buying conditions. Independence from individual states or banks and privacy protection are only perceived slightly better. In contrast, transparent process documentation, the protection against transactions' manipulation and the perception of legal risks positively stand out.

\subsection{Pairwise Comparisons (PC) (Indirect Proof of the Research Model)}

As Figure 4 reveals, security aspects, especially the protection of personal data and against fraud, seem to be very important in the context of automated online transactions compared to other properties. The possibility to specify further criteria (e.g. the delivery date) in combination with an option to refuse the app's recommendation, called "Freedom of decision (customisable attributes)", and the additional consideration of manufacturers' stores for price comparison, called "Independence from ordering platforms", are also relevant. In contrast, the app's permanent availability and low costs of payment execution appear to be relatively unimportant. However, this result should

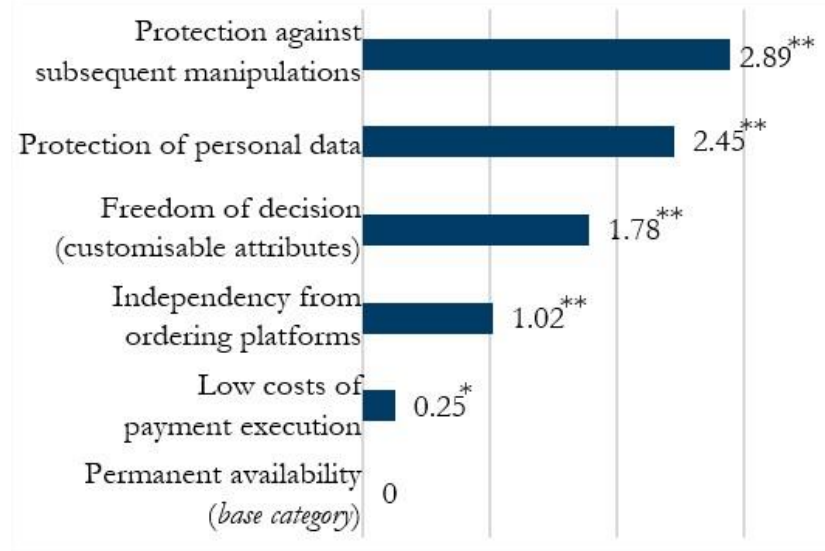

Figure 4. Pairwise Comparisons.

\section{Legend:}

values represent parameters of a Bradley-Terry-Luce-Test with "Permanent availability" as pre-defined base category.

* / ** - significantly different from base category at $10 \% / 1 \%$ level not be misinterpreted, because the importance of availability might only be realised if problems occur and referring to costs, these might have become elusive, because no concrete values were introduced.

\subsection{Structural Equation Model (SEM) (Direct Proof of the Research Model)}

Figure 5 (on the next page) displays the estimated SEM. Evaluating model's quality, the coefficients of determination $\left(\mathrm{R}^{2}\right)$ can be interpreted as "satisfying" regarding Usage Intention $\left(\mathrm{R}^{2}=0.294\right)$ and $\mathrm{PR}\left(\mathrm{R}^{2}=0.327\right)$ and as "substantial" for PU $\left(\mathrm{R}^{2}=0.513\right)$ due to the many potential determinants [41]. Considering multicollinearity between constructs and the items in case of formative variables, variance inflation factors should be regarded [44]: all range from 1.0 to 1.8 (for details, see Table 8), which is far below widely accepted maximum values of 5 or 10 . For addressing PEOU, factor loadings indicate sufficient internal consistency (all above 0.7) [41]. Bootstrapping reveals that all hypothesis can be confirmed at 10\% significance level and besides $\mathrm{H} 5$ all even at 5\%. In consequence, validity of the SEM can be assumed.

In addition to path coefficients (cf. Figure 5), that already allow a first indication of effect sizes, $\mathrm{F}^{2}$ is calculated for each relationship (cf. Table 9). Considering direct determinants of Usage Intention, Trialability, which clearly depends on PEOU $\left(\mathrm{F}^{2}=0.200\right)$, emerges as strongest $\left(\mathrm{F}^{2}=0.192\right)$, while PU $\left(\mathrm{F}^{2}=\right.$ $0.111)$ and PRK $\left(F^{2}=0.059\right)$ have a comparatively small, but unambiguous effect on it. Perceived Improvement of Buying Conditions has a remarkable influence on PU $\left(\mathrm{F}^{2}=0.723\right)$ and the Felt Independence from Institutions reduces PR strongly $\left(\mathrm{F}^{2}=0.485\right)$. Finally, it appears suitable to model $\mathrm{PR}$ as a determinant of PU having an indirect effect on Usage Intention only $\left(\mathrm{F}^{2}=0.137\right)$. Looking at items' weighting factors to form latent variables, summarised in Table 8, indirect conclusions can be drawn [44]:xiv Felt Independence from Institutions is surprisingly dominated by perceived independence from individual states $(\gamma=0.435)$ and technology groups $(\gamma=0.660)$, whereby it should be noted that the latter's effect might be affected by privacy improvements addicted to independence from technology groups [9]. PR extensively consists of the perception, that predominantly criminals use BCT $(\gamma=0.505)$, but obviously other influence factors also contribute to BCT's application being perceived as generally "risky" $(\gamma=0.485)$ and associated to potential losses $(\gamma=0.330)$. Lastly, PU strongly depends on the expected transaction costs $(\gamma=0.322)$, which is in line with findings regarding Perceived Improvement of 


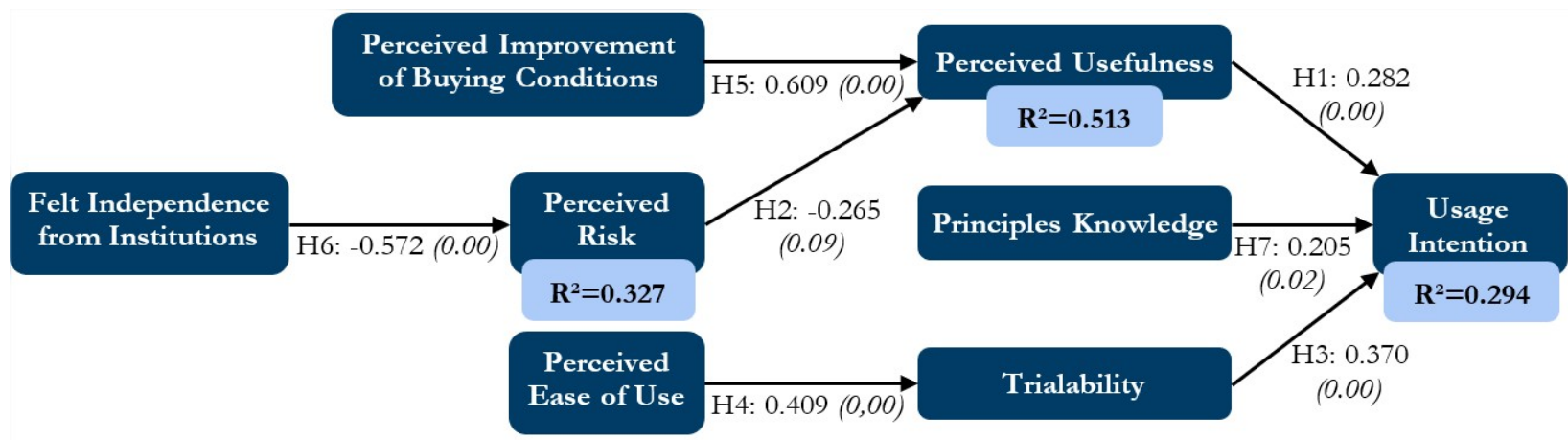

Figure 5. Structural Equation Model.

Legend: hypothesis (cf. part 3) $\longrightarrow$ H6: $-0.572(0.00)-$ error term (calculated by Bootstrapping-procedure)
standardised path coefficient

Buying Conditions, as well as on perceived privacy protection $(\gamma=0.341)$ and a general value perception of BCT usage $(\gamma=$ $0.536)$.

\subsection{Integration of Results}

To sum it up, consumers miss possibilities to try out BCT which they perceive to be very complex. Maybe because of their low knowledge of the disrupting ideas or principles the technology is based on, they do not realise how they can personally benefit from it. Finally, the following four beliefs regarding BCT are found to be specifically critical for stimulating acceptance:

- Expected Improvement of Transaction Conditions (derived from SEM)

- Perceived Privacy Protection (derived from PC and SEM)

- Felt Independence from Institutions (derived from SEM and indicated by PC)

- Perceived Fraud Protection (derived from PC and SEM)

\section{Discussion}

The results allow for concluding implications from the perspective of multiple stakeholders. The stated lack of legal certainty, for example, emphasises the importance of closing gaps in the law, e.g. in Data Protection Law [45] or Contract Law [46]. But in the following, the focus will be on suitable communication strategies to form desirable beliefs about BCT and on recommendable directions of the technology's further (technical) development. Final remarks, moreover, discuss conclusions for future research.

\subsection{Communication Strategies Towards Consumers}

(Persuasive) communication is a well-established instrument to form desirable beliefs [13]. The following recommendations are relevant for all institutions that might be interested in stimulating the diffusion of BCT (e.g. governmental ministries) or of applications based on BCT (e.g. start-up companies), because the general attitude towards the technology's usage profits from application's image whenever referring to BCT (e.g. in advertising) and vice versa ("image transfer"). Although target groups for communication should be defined contextand application-specific, general recommendations can be derived from the results by applying the already introduced Diffusion Theory (cf. part 3), which differentiates human stereotypes, called "Adopter Types", by their innovativeness [for this and below: 33]. The first to adopt are "Innovators", typically interacting with other Innovators, who are adventuresome, risk-seeking and have the ability to understand complex innovations. They serve as "gatekeepers" for a technology's diffusion and inspire "Early Adopters", who regularly catch up on new trends and enjoy to be local opinion leaders. Members of the "Early Majority" carefully weigh up innovations' usage and thereby refer to Early Adopters, who in consequence are crucial for reaching a critical mass.

Now comparing the percentage of actual BCT users (3.2\%) with the estimated percentage of innovators in the population (ca. $2.5 \% \mathrm{xv}$ ) [for this and below: 33], one can conclude that the Innovators already use BCT by a majority. In contrast, Early Adopters (ca. 13.5\% of the population) typically have already formed an intention to use the technology, but hesitate to use it (which is true for $12.1 \%$ of respondents) and thus are critical 
for the technology's further adoption, especially considering their influence on later Adopters. Early Adopters, for example, could be targeted by using methods discussed in the context of "Influencer Marketing" due to their increased use of Social Media, reasoned by their intense need for social participation. As regards content, possibilities to use BCT might be communicated (increasing Trialability) by emphasising improvements through the technology with respect to critical beliefs carved out in part 5 (Expected Improvement of Transaction Conditions, etc.). Thereby, it might be advisable to refer to technical characteristics for enhancing Principles Knowledge, which entails the challenge to explain complex principles as comprehensibly as possible. However, most crucial for communication success might be the derivation of tangible benefits and additional possibilities through the use of BCT from technical characteristics. Early Adopters, for example, possibly need to realise that BCT enables them to choose the way and rules of social interaction independent of technology groups or states.

\subsection{Further Development of Blockchain-Based Applications}

General recommendations for further development address business model creators just as frontend- and backend developers of Blockchain-based applications. First of all, a focus on usability to increase PEOU and to enhance the user experience [47] as well as the passing-on of savings due to Blockchain usage to consumers to some extent (leading to improvements of transaction conditions for them) is generally advisable. The relevance of "Independence from Institutions" further invites small providers of Blockchain-based applications to use the technology to communicate increased Independence from Institutions to gain competitive advantage. Privacy protection can be ensured by anonymity, which, however, is not guaranteed only because pseudonyms are used [17] and might be opposed to legal certainty. Anyway, only putting data "onchain" that are necessary for the functionality of an application and informing users about (reasons for) use of data [48] could also increase perceived privacy protection. To counter consumers' perceived risk to be defrauded, certifications for Blockchain solutions offered by trustworthy organisations based on transparent criteria [49] and insurances covering overestimated risks [4] are promising options. Continuing the development of solutions for the protection of private keys could further contribute to perceived risk reduction [50].

\subsection{Research Implications and Final Remarks}

From a researcher's perspective, a new, Blockchain-specific acceptance model has been developed, which delivers an explorative starting point for further acceptance research addressing BCT and some interesting findings for technology acceptance research in general. In particular, the interpretation of PEOU as an essential determinant of Trialability in the context of emerging technologies that has only occasionally been applied in the past [34] and the consideration of PR as influencing factor of $\mathrm{PU}$ whenever risk reduction is a constituting idea behind a technology's usage might inspire future research.

Of course, this paper faces many limitations: first of all, only usage intention and not actual usage is explained and no representativeness for the German population ensured. Furthermore, it leaves the explicit consideration of hedonic usage motives and expected changes of the interaction in social systems to future research. Although many of the indicated effects are probably valid for consumers from other countries than Germany, cultural differences, in particular in terms of technology usage habits, as well as country-specific requirements depending on legal circumstances and the technical infrastructure [21] might restrict international transferability. Moreover, technical trade-offs in Blockchain designs (e.g. between usability and security) leading to limits in evoking desirable perceptions at the same time have not been regarded [51]. Finally, some might argue that it only makes sense to research the acceptance of specific applications and not of the underlying technology because of the diversity of applications and designs. However, even for acceptance research on the application level, which is expected to increasingly follow in the future, this paper provides indications for research designs as well as for critical beliefs determining consumers' acceptance that is considered to be of outstanding importance to help the Blockchain technology fulfil its potential.

\section{Appendix:}


Table 1. Derivation of theory-based beliefs.

\begin{tabular}{|c|c|c|c|}
\hline $\begin{array}{l}\text { Theory-based } \\
\text { belief }\end{array}$ & $\begin{array}{l}\text { Corresponding } \\
\text { theory }\end{array}$ & $\begin{array}{l}\text { Subordinate beliefs relevant in } \\
\text { Blockchain context (selection) }\end{array}$ & $\begin{array}{l}\text { Corresponding characteristics of Blockchain } \\
\text { applications (selection) [51] }\end{array}$ \\
\hline \multirow[t]{3}{*}{$\begin{array}{l}\text { Perceived } \\
\text { Usefulness }\end{array}$} & \multirow[t]{3}{*}{ TAM } & $\begin{array}{l}\text { Perceived increase of transparency } \\
{[17,18,19,22]}\end{array}$ & $\begin{array}{l}\text { Availability }(+) \\
\text { Consistency }(+) \\
\text { Vulnerability Resistance }(+)\end{array}$ \\
\hline & & $\begin{array}{l}\text { Expected reduction in transaction } \\
\text { costs }^{*}[4,17,18,19,22]\end{array}$ & $\begin{array}{l}\text { (low) direct, monetary transaction costs }(+) \\
\text { (low) indirect transaction costs }(+) \text { (e.g. required time } \\
\text { depending on transaction validation speed and the } \\
\text { effort that is necessary to find a transaction partner) }\end{array}$ \\
\hline & & $\begin{array}{l}\text { Perceived improvement of privacy } \\
\text { protection* }[4,17]\end{array}$ & $\begin{array}{l}\text { Confidentiality }(+) \text { (e.g. enabled by pseudonymity, } \\
\text { applied encryption methods or user-managed data } \\
\text { exchange) } \\
\text { Integrity }(+)\end{array}$ \\
\hline $\begin{array}{l}\text { Perceived Ease } \\
\text { of Use }\end{array}$ & TAM & Usability perception $[17,18]$ & $\begin{array}{l}\text { Interoperability between applications }(+) \\
\text { Exchangeability of cryptocurrencies }(+) \\
\text { Response time }(-) \\
\text { Support for constrained devices }(+)\end{array}$ \\
\hline \multirow[t]{2}{*}{ Perceived Risk } & \multirow[t]{2}{*}{ TAM, extended } & $\begin{array}{l}\text { Perception of fraud risks }[4,17,18, \\
19,22]\end{array}$ & $\begin{array}{l}\text { Confidentiality (-) } \\
\text { Consistency }(-) \\
\text { Integrity }(-) \text { (especially tamper-resistant logging) } \\
\text { Decentralisation }(-) \\
\text { Vulnerability resistance }(-)\end{array}$ \\
\hline & & \multicolumn{2}{|c|}{ For more detailed discussion of risks associated with BCT usage, see [4] } \\
\hline Trialability & $\begin{array}{l}\text { Diffusion } \\
\text { Theory }\end{array}$ & Accessibility $[4,17,18,19,22]$ & $\begin{array}{l}\text { Availability }(+) \\
\text { Interoperability between applications }(+) \\
\text { Required bandwidth }(-) \\
\text { Support for constrained devices }(+)\end{array}$ \\
\hline
\end{tabular}

Table 2. Derivation of technology-based beliefs.

\begin{tabular}{|l|l|l|}
\hline $\begin{array}{l}\text { Technology- } \\
\text { based belief }\end{array}$ & $\begin{array}{l}\text { Subordinate beliefs } \\
\text { relevant in Blockchain } \\
\text { context (selection) }\end{array}$ & $\begin{array}{l}\text { Constituting characteristics of Blockchain applications [51] } \\
\text { For argumentation regarding independence, compare [4] }\end{array}$ \\
\hline $\begin{array}{l}\text { Felt } \\
\text { Independence } \\
\text { from } \\
\text { Institutions }\end{array}$ & $\begin{array}{l}\text { Independence from } \\
\text { technology groups* }\end{array}$ & $\begin{array}{l}\text { Possible consequence of disintermediation and... } \\
\ldots \text { decentralisation by taking over services of technology groups or banks enabled by } \\
\text { BCT (independence from technology groups and banks) } \\
\text { or respectively } \\
\ldots \text { the international distribution of power to change consensus (independence from } \\
\text { states) }\end{array}$ \\
\cline { 2 - 3 } & $\begin{array}{l}\text { Independence from } \\
\text { banks* }\end{array}$ & $\begin{array}{l}\text { These processes are enabled by BCT's characteristics, especially by Availability, } \\
\text { Confidentiality, Consistency, Integrity, Encryption, Resilience, Vulnerability resistance, } \\
\text { (low) costs (of transactions), Ease of Node Adoption, Support for constrained devices }\end{array}$ \\
\cline { 2 - 3 } & $\begin{array}{l}\text { Independence from } \\
\text { states* }\end{array}$ & $\begin{array}{l}\text { speed and indirectly by transparency-induced (potential) gain of power in transactional } \\
\text { relations as a consequence of market transparency and disintermediation [9] }\end{array}$ \\
\hline $\begin{array}{l}\text { Perceived } \\
\text { Improvement } \\
\text { of Buying } \\
\text { Conditions }\end{array}$ & $\begin{array}{l}\text { Expected price } \\
\text { conditions }\end{array}$ & \\
\cline { 2 - 3 }
\end{tabular}

Table 3. Adaptive design of the online questionnaire. 


\begin{tabular}{|l|l|l|}
\hline $\begin{array}{l}\text { Part of the online } \\
\text { questionnaire }\end{array}$ & Abbreviation & $\begin{array}{l}\text { Number of } \\
\text { participants }\end{array}$ \\
\hline General technology use & GT & 157 \\
\hline BCT: general beliefs & BG & 73 \\
\hline BCT: specific beliefs & BS & 32 \\
\hline $\begin{array}{l}\text { Pairwise Comparisons } \\
\text { (attributes of a new app) }\end{array}$ & PC & 102 \\
\hline Personal data & PD & 128 \\
\hline $\begin{array}{l}\text { Blockhain-Quiz } \\
\text { (appendix) }\end{array}$ & QU & 49 \\
\hline
\end{tabular}

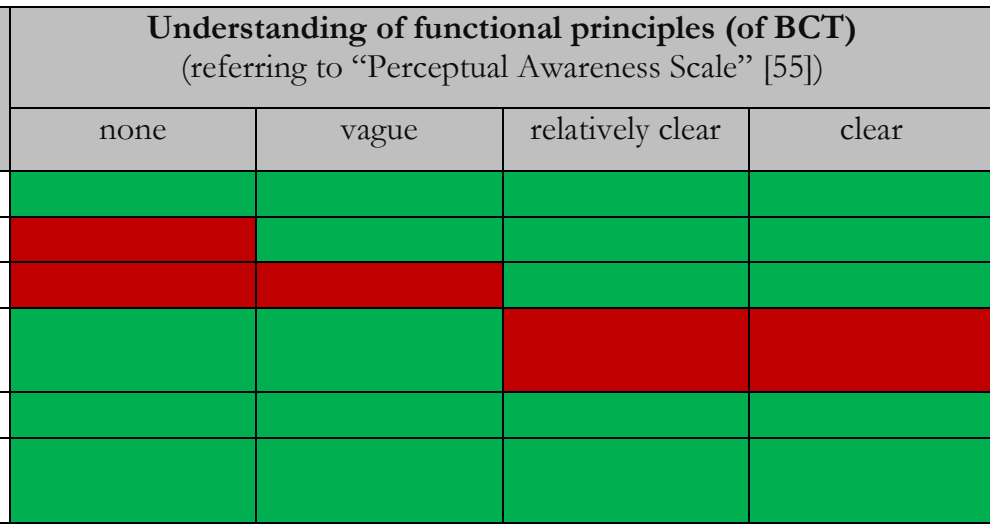

Legend: displayed

BCT = Blockchain technology

The number of participants includes all who answered at least one question of the part.

Table 4. Measurement models in the Structural Equation Model.

\begin{tabular}{|c|c|c|c|c|}
\hline Latent variable & $\begin{array}{l}\text { Type of } \\
\text { measure- } \\
\text { ment }\end{array}$ & $\begin{array}{l}\text { Item's description } \\
\text { (cf. Table } 6 \text { and Table 7) }\end{array}$ & $\begin{array}{l}\text { Questionnaire } \\
\text { part (cf. Table 3) }\end{array}$ & $\begin{array}{l}\text { Origin of item's scale } \\
\text { (BC = measured in a } \\
\text { Blockchain context) }\end{array}$ \\
\hline \multirow[t]{4}{*}{ Perceived Usefulness } & \multirow[t]{4}{*}{ Formative } & BCT use valuable & BG & \multirow{4}{*}{$\begin{array}{l}{[29]} \\
{[22(\mathrm{BC})]}\end{array}$} \\
\hline & & Privacy protection & BS & \\
\hline & & Low transaction costs & BS & \\
\hline & & BCT useful & BG & \\
\hline \multirow{2}{*}{$\begin{array}{l}\text { Perceived Ease of } \\
\text { Use }\end{array}$} & \multirow[t]{2}{*}{ Reflective } & BCT easy to understand & BG & \multirow{2}{*}{$\begin{array}{l}{[26,29,56]} \\
{[20(\mathrm{BC})]}\end{array}$} \\
\hline & & BCT use easy to learn & BG & \\
\hline \multirow[t]{3}{*}{ Perceived Risk } & \multirow[t]{3}{*}{ Formative } & BCT use risky & BG & \multirow{3}{*}{$\begin{array}{l}{[29]} \\
{[22(\mathrm{BC})]}\end{array}$} \\
\hline & & Damage from BCT use & BG & \\
\hline & & Criminal users of BCT & BG & \\
\hline \multirow{3}{*}{$\begin{array}{l}\text { Felt Independence } \\
\text { from Institutions }\end{array}$} & \multirow[t]{3}{*}{ Formative } & Independence from technology groups & BS & \multirow[t]{3}{*}{ / } \\
\hline & & Independence from banks & BS & \\
\hline & & Independence from states & BS & \\
\hline \multicolumn{3}{|c|}{ Perceived Improvement of Buying Conditions } & BS & / \\
\hline \multicolumn{3}{|c|}{ Trialability } & BG & {$[56]$} \\
\hline \multicolumn{3}{|l|}{ Principles Knowledge } & QU & {$[43]$} \\
\hline \multicolumn{3}{|l|}{ Usage Intention } & GT & / (dichotomous) \\
\hline
\end{tabular}

Legend: BCT $=$ Blockchain technology

All scales used were translated into German and thereby partially slightly modified.

Table 5. Blockchain-quiz - questions and results.

\begin{tabular}{|c|c|c|c|c|c|c|}
\hline & $\begin{array}{l}\text { Ques- } \\
\text { tion } \\
\text { Nr. }\end{array}$ & Question text & $\begin{array}{l}\text { Correct } \\
\text { answer }\end{array}$ & $\begin{array}{l}\text { Share of } \\
\text { correct } \\
\text { answers }\end{array}$ & $\begin{array}{l}\text { Ø Con- } \\
\text { fidence } \\
\text { rating }\end{array}$ & $\begin{array}{l}\text { Score }(\varnothing=\text { average } / \\
\mathrm{SD}=\text { standard deviation })\end{array}$ \\
\hline \multirow{6}{*}{$\begin{array}{l}\text { How- } \\
\text { to- } \\
\text { Knowl- } \\
\text { edge } \\
\text { (HTK) }\end{array}$} & 1 & Recipient's public key is needed to initiate a transaction & true & $49 \%$ & 1,77 & $\varnothing=+6,3 / \mathrm{SD}=31,0$ \\
\hline & 2 & Recipient's private key is needed to initiate a transaction & false & $27 \%$ & 1,98 & $\varnothing=-2,8 / \mathrm{SD}=31,7$ \\
\hline & 3 & Private and public keys consist of numbers and letters & true* & $84 \%$ & 2,27 & $\varnothing+30,9 / \mathrm{SD}=21,4$ \\
\hline & 4 & $\begin{array}{l}\text { On prevalent Blockchains, transactions are approved by } \\
\text { an authorised participant (central authority) }\end{array}$ & false & $63 \%$ & 2,06 & $\varnothing=+19,6 / \mathrm{SD}=28,0$ \\
\hline & 5 & $\begin{array}{l}\text { New transactions are immediately incorporated into the } \\
\text { Blockchain }\end{array}$ & false & $33 \%$ & 2,06 & $\varnothing=-6,1 / \mathrm{SD}=33,5$ \\
\hline & \multicolumn{3}{|l|}{ Total } & $51 \%$ & 2,03 & $\varnothing=+9,57 / \mathrm{SD}=68,1$ \\
\hline \multirow{2}{*}{$\begin{array}{l}\text { Princi- } \\
\text { ples }\end{array}$} & 6 & Each block has one specific predecessor & true & $79 \%$ & 1,91 & $\varnothing=+21,6 / \mathrm{SD}=26,2$ \\
\hline & 7 & Usually, multiple transactions are assigned to a block & true & $62 \%$ & 1,72 & $\varnothing=+18,0 / \mathrm{SD}=25,5$ \\
\hline
\end{tabular}




\begin{tabular}{|c|c|c|c|c|c|c|}
\hline \multirow{4}{*}{$\begin{array}{l}\text { Knowl- } \\
\text { edge } \\
\text { (PRK) }\end{array}$} & 8 & Usually, a transaction is distributed to multiple blocks & false & $60 \%$ & 1,60 & $\varnothing=+15,0 / \mathrm{SD}=24,7$ \\
\hline & 9 & $\begin{array}{l}\text { On public (permissionless) Blockchains, all transactions } \\
\text { are typically visible for all participants }\end{array}$ & true & $79 \%$ & 1,64 & $\varnothing=+24,8 / \mathrm{SD}=20,6$ \\
\hline & 10 & $\begin{array}{l}\text { If "proof-of-stake" consensus mechanism is applied, a } \\
\text { miner's asset influences his chance to create an } \\
\text { upcoming block }\end{array}$ & true & $57 \%$ & 1,34 & $\varnothing=+9,4 / \mathrm{SD}=24,5$ \\
\hline & & & Total & $67 \%$ & 1,64 & $\varnothing=+88,8 / \mathrm{SD}=67,5$ \\
\hline \multicolumn{4}{|c|}{ Total HTK + PRK } & $59 \%$ & 1,84 & $\varnothing=+136,5 / \mathrm{SD}=107,7$ \\
\hline
\end{tabular}

Legend: $*$ if displayed in conventional hexadecimal system. Questions partly inspired by Henry et al. [14].

$\mathrm{n}=49$ (varies due to drop outs for each question; 46 participants answered all ten questions).

"Confidence Rating" is scaled from 0 (very unconfident) to 4 (very confident). Score ranges from -60 to +50 for each question, in consequence from -300 to +250 for HTK and PRK and from -600 to +500 in total.

Table 6. Beliefs about Blockchain technology (BCT).

\begin{tabular}{|l|l|l|l|l|}
\hline $\begin{array}{l}\text { Item } \\
\text { Nr. }\end{array}$ & Item Text & Item description & $\begin{array}{l}\text { Average } \\
\text { (ranges from } \\
\text { 0 to 4) }\end{array}$ & $\begin{array}{l}\text { Standard } \\
\text { deviation } \\
\text { (in scale points) }\end{array}$ \\
\hline 1 & The use of Blockchain technology is valuable for me & BCT use valuable & 1.98 & 1.09 \\
\hline 2 & The technology is useful & BCT useful & 3.25 & 0.70 \\
\hline 3 & Blockchain technology is easy to understand & BCT easy to understand & 1.24 & 0.90 \\
\hline 4 & Technology's application is easy to learn & BCT use easy to learn & 1.69 & 1.09 \\
\hline 5 & The application of Blockchain technology is risky & BCT use risky & 1.57 & 1.16 \\
\hline 6 & Using the technology can cause substantial damage for me & Damage from BCT use & 1.64 & 0.98 \\
\hline 7 & Blockchain technology is predominately used by criminals & Criminal users of BCT & 1.23 & 0.81 \\
\hline 8 & I know how to try out Blockchain applications & Trialability & 1.77 & 1.42 \\
\hline 9 & Others expect me to use Blockchain technology & $\begin{array}{l}\text { Social Norm } \\
\text { (not part of SEM) }\end{array}$ & 0.80 & 1.06 \\
\hline
\end{tabular}

Legend: items were measured in questionnaire part "BG" (cf. Table 3).

SEM = Structural Equation Model. Corresponding question: how strongly do you agree with the following statements concerning the Blockchain technology?

$\mathrm{n}=70$; participants stating "cannot judge" were filtered out. In consequence, actually considered responses for each item range from 45 to 64 . Scale points are named the following:

0 (minimum) - fully disagree $\mid 1$ - rather disagree $\mid 2$ - neither agree nor disagree $\mid 3$-rather agree $\mid 4$ (maximum) - fully agree

Table 7. Specific beliefs about Blockchain technology (BCT).

\begin{tabular}{|c|c|c|c|c|}
\hline $\begin{array}{l}\text { Item } \\
\text { Nr. }\end{array}$ & $\begin{array}{l}\text { Item text } \\
\text { "Blockchain applications..." }\end{array}$ & Item description & $\begin{array}{l}\text { Average } \\
\text { (ranges } \\
\text { from } 0 \text { to 4) }\end{array}$ & \begin{tabular}{|l|} 
Standard \\
deviation \\
(scale points)
\end{tabular} \\
\hline 10 & "...make me independent from technology groups" & $\begin{array}{l}\text { Independence from } \\
\text { technology groups }\end{array}$ & 2.32 & 1.06 \\
\hline 11 & “...make me independent from banks" & Independence from banks & 2.76 & 1.02 \\
\hline 12 & "...make me independent from individual states" & Independence from states & 2.42 & 1.07 \\
\hline 13 & "... are characterised by low costs per transaction" & Low transaction costs & 2.04 & 1.34 \\
\hline 14 & “...protect my privacy" & Privacy protection & 2.46 & 1.07 \\
\hline \multirow[t]{2}{*}{15} & $\begin{array}{l}\text { "...improve the conditions at which I can buy goods and } \\
\text { services" }\end{array}$ & $\begin{array}{l}\text { Perceived Improvement of } \\
\text { Buying Conditions }\end{array}$ & 1.91 & 1.24 \\
\hline & \multicolumn{4}{|l|}{ Perception of selected functionalities } \\
\hline 16 & $" \ldots$ can record processes transparently" & $\begin{array}{l}\text { Transparent process } \\
\text { documentation }\end{array}$ & 3.03 & 0.87 \\
\hline 17 & “...preclude the manipulation of transactions" & Manipulation resistance & 2.71 & 1.21 \\
\hline \multirow[t]{2}{*}{18} & $\begin{array}{l}\text { "...preclude the execution of transactions in the name of } \\
\text { someone else" }\end{array}$ & No identity fraud & 1.58 & 1.10 \\
\hline & \multicolumn{4}{|l|}{ Risk perception } \\
\hline
\end{tabular}




\begin{tabular}{|l|l|l|l|l|}
\hline 19 & "...hold legal risks" & Legal risk & 2.60 & 1.00 \\
\hline 20 & “...hold the risk to loose money due to fraud” & Fraud risk & 2.10 & 1.15 \\
\hline 21 & $\begin{array}{l}\text { "...lack maturity and thus their usage could cause substantial } \\
\text { damage to me“ }\end{array}$ & Maturity risk & 1.86 & 1.11 \\
\hline
\end{tabular}

Legend: items were measured in questionnaire part "BS" (cf. Table 3).

$\mathrm{n}=32$; participants stating "cannot judge" were filtered out. In consequence, actually considered responses for each item range from 23 to 29.

Corresponding question: how do you evaluate Blockchain applications generally regarding the following characteristics compared to currently used IT applications?

Scale points are named the following: 0 (minimum) - much less pronounced | 1 - little less pronounced | 2 - equally pronounced 3 - little more pronounced $\mid 4$ (maximum) - much more pronounced

Table 8. Accuracy of the Structural Equation Model.

\begin{tabular}{|c|c|c|c|}
\hline Latent variable & Item description (cf. Table 6 and Table 7) & $\begin{array}{l}\text { Coefficient } \beta \\
\text { (formative) / factor } \\
\text { loading } \mathbf{r} \text { (reflective) }\end{array}$ & $\begin{array}{l}\text { VIF (formative) / } \\
\text { reliability coefficient } \\
\varrho \text { (reflective/1-item) }\end{array}$ \\
\hline \multirow{4}{*}{$\begin{array}{l}\text { Perceived Usefulness } \\
\text { (PU) }\end{array}$} & BCT use valuable & $\beta=0.536$ & $\mathrm{VIF}=1.372$ \\
\hline & Privacy protection & $\beta=0.341$ & $\mathrm{VIF}=1.238$ \\
\hline & Low transaction costs & $\beta=0.322$ & $\mathrm{VIF}=1.174$ \\
\hline & BCT useful & $\beta=0.217$ & $\mathrm{VIF}=1.444$ \\
\hline \multirow{2}{*}{$\begin{array}{l}\text { Perceived Ease of Use } \\
\text { (PEOU) }\end{array}$} & BCT easy to understand & $\mathrm{r}=0.873$ & \multirow[t]{2}{*}{$\varrho=0.843$} \\
\hline & BCT use easy to learn & $\mathrm{r}=0.833$ & \\
\hline \multirow{3}{*}{$\begin{array}{l}\text { Perceived Risk } \\
(\mathrm{PR})\end{array}$} & BCT use risky & $\beta=0.485$ & $\mathrm{VIF}=1.365$ \\
\hline & Damage from BCT use & $\beta=0.330$ & $\mathrm{VIF}=1.425$ \\
\hline & Criminal users of BCT & $\beta=0.505$ & $\mathrm{VIF}=1.140$ \\
\hline \multirow{7}{*}{$\begin{array}{l}\text { Felt Independence from } \\
\text { Institutions }\end{array}$} & Independence from technology groups & $\beta=0.660$ & $\mathrm{VIF}=1.079$ \\
\hline & Independence from banks & $\beta=0.254$ & $\mathrm{VIF}=1.783$ \\
\hline & Independence from states & $\beta=0.435$ & $\mathrm{VIF}=1.689$ \\
\hline & Perceived Improvement of Buying Conditions & $\mathrm{r}=1.000$ (single item) & / \\
\hline & Trialability & $\mathrm{r}=1.000$ (single item) & / \\
\hline & Principles Knowledge & $\mathrm{r}=1.000($ single item $)$ & / \\
\hline & Usage Intention & $\mathrm{r}=1.000($ single item $)$ & / \\
\hline
\end{tabular}

Legend: VIF = variance inflation factor.

Table 9. Effect sizes of the Structural Equation Model.

\begin{tabular}{|l|l|l|l|l|l|}
\hline Hypothesis & Relation & $\mathrm{F}^{2} \mid$ effect strength & Hypothesis & Relation & $\mathbf{F}^{2} \mid$ effect strength \\
\hline H1 & PU $\rightarrow$ Intention & $\mathrm{F}^{2}=0.111 \mid$ small & H5 & Conditions $\rightarrow$ PU & $\mathrm{F}^{2}=0.723 \mid$ strong \\
\hline H2 & PR $\rightarrow$ PU & $\mathrm{F}^{2}=0.137 \mid$ small & H6 & Independence $\rightarrow$ PR & $\mathrm{F}^{2}=0.485 \mid$ strong \\
\hline H3 & Trialability $\rightarrow$ Intention & $\mathrm{F}^{2}=0.192 \mid$ medium & H7 & $\begin{array}{l}\text { Principles Knowledge } \\
\rightarrow \text { Intention }\end{array}$ & $\mathrm{F}^{2}=0.059 \mid$ small \\
\hline H4 & PEOU $\rightarrow$ Trialability & $\mathrm{F}^{2}=0.200 \mid$ medium & Legend: evaluation of effect strength based on Hair et al. [41] \\
\hline
\end{tabular}

Legend: PU = Perceived Usefulness $\quad$ PEOU = Perceived Ease of Use $\quad$ PR = Perceived Risk

\section{Competing Interests:}

None declared.

Ethical approval:

Not applicable.
Funding:

None declared.

Acknowledgements:

None declared. 


\section{References:}

[1] S. Nakamoto, "Bitcoin: A peer-to-peer Electronic cash system”, 2008. [Online]. Available: https://bitcoin.org/bitcoin.pdf. [Accessed: June 04, 2019].

[2] V. Morabito, "Business innovation through blockchain", Cham: Springer International Publishing, 2017.

[3] YouGov Deutschland GmbH, "Blockchain Revolution: How Blockchain-Technology will change the Financial Sector from a Consumer's Perspective". [Original title] "Blockchain-Revolution: Wie die Blockchain-Technologie die Finanzwelt aus Verbrauchersicht ändern wird”, 2017. [Online]. Available: https://yougov.de/news/2017/09/04/blockchain-als-nachstestufe-des-internets/. [Accessed: June 07, 2019].

[4] S. Abramova and R. Böhme, "Perceived Benefit and Risk as Multidimensional Determinants of Bitcoin Use: A Quantitative Exploratory Study", in Proceedings of the 37th International Conference on Information Systems (ICIS), Dublin, Ireland, pp. 120, 2016.

[5] S. Davidson, P. De Filippi and J. Potts, "Economics of Blockchain", SSRN Journal, 2016. [Online]. Available: https://papers.ssrn.com/sol3/papers.cfm?abstract_id=2744751. [Accessed: June 07, 2019].

[6] C. R. Harvey, C. Moorman and M. Toledo, "How Blockchain Will Change Marketing As We Know It”, SSRN Journal, 2018. [Online]. Available:

https://papers.ssrn.com/sol3/papers.cfm?abstract_id=3257511. [Accessed: June 26, 2019].

[7] G. Zyskind, O. Nathan and A. 'S.' Pentland, “Decentralizing Privacy: Using Blockchain to Protect Personal Data", in 2015 IEEE Security and Privacy Workshops, San Jose, California, USA, pp. 180-184, 2015.

[8] A. Hayes, "The Socio-Technological Lives of Bitcoin", Theory, Culture \& Society, vol. 36, no. 4, pp. 49-72, 2019.

[9] L. W. Cong and Z. He, "Blockchain disruption and smart contracts", The Review of Financial Studies, vol. 32, no. 5, pp. 1754-1797, 2019.

[10] N. Jonker, "What Drives Bitcoin Adoption by Retailers", SSRN Journal, 2018. [Online]. Available: https://papers.ssrn.com/sol3/papers.cfm?abstract_id $=3134404$. [Accessed: June 07, 2019].

[11] A. Schwarz and W. Chin, "Looking forward: Toward an understanding of the nature and definition of IT acceptance", Journal of the Association for Information Systems, vol. 8, no. 4, pp. 230-243, 2007.

[12] V. Venkatesh, M. G. Morris and F. D. Davis, "User Acceptance of Information Technology: Toward a Unified View", MIS Quarterly, vol. 27, no. 3, pp. 425-478, 2003.

[13] M. Fishbein and I. Ajzen, "Predicting and changing behavior: The reasoned action approach", New York: Psychology Press, 2010.

[14] C. S. Henry, K. P. Huynh and G. Nicholls, "Bitcoin Awareness and Usage in Canada", in Bank of Canada Staff Working Paper, no. 56, 2017. [Online]. Available: https://www.bankofcanada.ca/wp-

content/uploads/2017/12/swp2017-56.pdf. [Accessed: June 07, 2019].

[15] S. Schuh and O. Shy, "U.S. Consumers' Adoption and Use of Bitcoin and other Virtual Currencies", 2015. [Online]. Available: https://www.bankofcanada.ca/wp-content/uploads/2015/12/usconsumers-adoption.pdf. [Accessed: June 07, 2019].
[16] Hongkong \& Shanghai Banking Corporation Holdings PLC, "Trust in Technology", 2017. [Online]. Available: http://www.hsbc.com/trust-in-technology-report. [Accessed: June 07, 2019].

[17] D. Folkinshteyn and M. Lennon, "Braving Bitcoin: A technology acceptance model (TAM) analysis", Journal of Information Technology Case and Application Research, vol. 18, no. 4, pp. 220 249, 2016.

[18] A. W. Baur, J. Bühler, M. Bick and C. S. Bonorden, "Cryptocurrencies as a Disruption? Empirical Findings on User Adoption and Future Potential of Bitcoin and Co", in Lecture notes in computer science, Open and Big Data Management and Innovation, M. Janssen, M. Mäntymäki, J. Hidders, B. Klievink, W. Lamersdorf, B. van Loenen and A. Zuiderwijk, Eds., Cham: Springer International Publishing, pp. 63-80, 2015.

[19] J. M. Woodside, F. K. Augustine Jr. and W. Giberson, "Blockchain Technology Adoption Status and Strategies", Journal of International Technology and Information Management, vol. 26, no. 2, pp. 65-93, 2017.

[20] K. Francisco and D. Swanson, "The Supply Chain Has No Clothes: Technology Adoption of Blockchain for Supply Chain Transparency”, Logistics, vol. 2, no. 1, 2018.

[21] M. M. Queiroz and S. Fosso Wamba, "Blockchain adoption challenges in supply chain: An empirical investigation of the main drivers in India and the USA", International Journal of Information Management, vol. 46, pp. 70-82, 2019.

[22] A. Kumpajaya and W. Dhewanto, "The acceptance of Bitcoin in Indonesia: Extending TAM with IDT," Journal of Business and Management, vol. 4, no. 1, pp. 28-38, 2015

[23] D. Montaño and D. Kasprzyk, "Theory of Reasoned Action, Theory of Planned Behavior, and the Integrated Behavioral Model", in Health behavior and health education: Theory, research, and practice, K. Glanz, B. K. Rimer, K. Viswanath and C. T. Orleans, Eds., 4th ed. San Francisco: Jossey-Bass, pp. 67-96, 2008.

[24] R. H. Fazio and T. Towles-Schwen, "The MODE model of attitudebehavior processes", in Dual-process theories in social psychology, S. Chaiken and Y. Trope, Eds., New York: Guilford Press, pp. 97116, 1999 .

[25] F. D. Davis, "A Technology Acceptance Model for Empirically Testing New End-User Information Systems". PhD [Dissertation]. Cambridge: Massachusetts Institute of Technology, 1985. [Online]. Available: https://www.researchgate.net/publication/35465050_A_Technolo gy_Acceptance_Model_for_Empirically_Testing_New_EndUser_Information_Systems. [Accessed: June 07, 2019].

[26] S. Kulviwat, G. C. Bruner II, A. Kumar, S. A. Nasco and T. Clark, "Toward a unified theory of consumer acceptance technology", Psychology \& Marketing, vol. 24, no. 12, pp. 1059-1084, 2007.

[27] F. D. Davis, "Perceived Usefulness, Perceived Ease of Use, and User Acceptance of Information Technology", MIS Quarterly, vol. 13, no. 3, pp. 319-340, 1989

[28] V. Venkatesh and F. D. Davis, "A Theoretical Extension of the Technology Acceptance Model: Four Longitudinal Field Studies", Management Science, vol. 46, no. 2, pp. 186-204, 2000.

[29] P. A. Pavlou, "Consumer Acceptance of Electronic Commerce: Integrating Trust and Risk with the Technology Acceptance Model", International Journal of Electronic Commerce, vol. 7, no. 3, pp. 101-134, 2003.

[30] K. Nærland, C. Müller-Bloch, R. Beck and S. Palmund, "Blockchain to Rule the Waves-Nascent Design Principles for Reducing Risk and Uncertainty in Decentralized Environments", in Proceedings of 
the $38^{\text {th }}$ International Conference on Information Systems (ICIS), Seoul, South Korea, pp. 3885-3990, 2017.

[31] P. Legris, J. Ingham and P. Collerette, "Why do people use information technology? A critical review of the technology acceptance model", Information \& Management, vol. 40, no. 3, pp. 191-204, 2003.

[32] K. Mathieson, "Predicting User Intentions: Comparing the Technology Acceptance Model with the Theory of Planned Behavior", Information Systems Research, vol. 2, no. 3, pp. 173 191,1991

[33] E. M. Rogers, "Diffusion of innovations", $5^{\text {th }}$ ed., New York, London, Toronto, Sydney: Free Press, 2003.

[34] K. K. Kapoor, Y. K. Dwivedi and M. D. Williams, "Rogers" Innovation Adoption Attributes: A Systematic Review and Synthesis of Existing Research", Information Systems Management, vol. 31, no. 1, pp. 74-91, 2014

[35] S. Chakrabarty, G. Brown and R. E. Widing, "The Effects of Perceived Customer Dependence on Salesperson Influence Strategies", Journal of Personal Selling \& Sales Management, vol. 30, no. 4, pp. 327-341, 2010.

[36] R. Frey, D. Wörner and A. Ilic, "Collaborative Filtering on the Blockchain: A Secure Recommender System for e-Commerce", in Surfing the IT innovation wave: $22^{\text {nd }}$ Americas Conference on Information Systems (AMCIS), San Diego, USA, pp. 1734-1738, 2016.

[37] N. Dodd, “The Social Life of Bitcoin", Theory, Culture \& Society, vol. 35, no. 3, pp. 35-56, 2018.

[38] R. A. Bradley and M. E. Terry, "Rank Analysis of Incomplete Block Designs: I. The Method of Paired Comparisons", Biometrika, vol. 39, no. 3/4, pp. 324-345, 1952.

[39] R. D. Luce, "Individual choice behavior: A theoretical analysis", Mineola: Dover Publications, 2005.

[40] J. R. Rossiter, "The C-OAR-SE procedure for scale development in marketing”, International Journal of Research in Marketing, vol. 19, no. 4, pp. 305-335, 2002

[41] J. F. Hair, G. T. M. Hult, C. M. Ringle and M. Sarstedt, “A primer on partial least squares structural equation modeling (PLS-SEM)", $2^{\text {nd }}$ ed., Los Angeles, London, New Delhi, Singapore, Washington DC, Melbourne: Sage, 2017.

[42] K. Seaborn and D. I. Fels, "Gamification in theory and action: A survey", International Journal of Human-Computer Studies, vol. 74, pp. 14-31, 2015.

[43] P. Hassmen and D. P. Hunt, "Human Self-Assessment in MultipleChoice Testing", Journal of Educational Measurement, vol. 31, no. 2, pp. 149-160, 1994

[44] S. B. MacKenzie, P. M. Podsakoff and C. B. Jarvis, "The problem of measurement model misspecification in behavioral and organizational research and some recommended solutions", The Journal of applied psychology, vol. 90, no. 4, pp. 710-730, 2005.

[45] J. Erbguth and G. Fasching, "Who is the Responsible Person of a Bitcoin Transaction? Applicability of the GDPR to the Bitcoin Blockchain". [Original title] "Wer ist Verantwortlicher einer Bitcoin-Transaktion? Anwendbarkeit der DS-GVO auf die BitcoinBlockchain", Zeitschrift für Datenschutz, vol. 7, no. 12, pp. 560$564,2017$.

[46] R. Böhme, N. Christin, B. Edelman and T. Moore, "Bitcoin: Economics, Technology, and Governance", Journal of Economic Perspectives, vol. 29, no. 2, pp. 213-238, 2015.
[47] V. Venkatesh, "Determinants of Perceived Ease of Use: Integrating Control, Intrinsic Motivation, and Emotion into the Technology Acceptance Model", Information Systems Research, vol. 11, no. 4, pp. 342-365, 2000 .

[48] E. Aguirre, A. L. Roggeveen, D. Grewal and M. Wetzels, "The personalization-privacy paradox: implications for new media", Journal of Consumer Marketing, vol. 33, no. 2, pp. 98-110, 2016.

[49] O. Labazova, T. Dehling and A. Sunyaev, "From Hype to Reality: A Taxonomy of Blockchain Applications”, in Proceedings of the 52nd Hawaii International Conference on System Sciences (HICSS 2019), Wailea, USA, 2018. [Online]. Available: https://papers.ssrn.com/sol3/papers.cfm?abstract_id=3250648. [Accessed: June 07, 2019].

[50] M. A. Khan and K. Salah, "IoT security: Review, Blockchain Solutions, and Open Challenges", Future Generation Computer Systems, vol. 82, pp. 395-411, 2018.

[51] N. Kannengießer, S. Lins, T. Dehling and A. Sunyaev, "What Does Not Fit Can be Made to Fit! Trade-Offs in Distributed Ledger Technology Designs", in Proceedings of the 52 nd Hawaii International Conference on System Sciences (HICSS 2019), Wailea USA, 2018. [Online]. Available:

https://www.researchgate.net/publication/327793246_What_Does _Not_Fit_Can_be_Made_to_Fit_Trade-

Offs_in_Distributed_Ledger_Technology_Designs [Accessed: June 07, 2019].

[52] [Cited in the endnotes]. J. Kolla, "Decoding the evolution of Blockchain 3.0", 2018. [Online]. Available: https://www.livemint.com/Technology/OIb3LaLJ2pdwAGMRCi GLhI/Decoding-the-evolution-of-Blockchain-30.html. [Accessed: June 07, 2019].

[53] [Cited in the endnotes]. Federal Statistical Offices, "Welcome to the census database of the Census 2011. Dynamic and individual results", 2011. [Online]. Available:

https://ergebnisse.zensus2011.de/?locale $=$ en. [Accessed: July 04, 2019].

[54] [Cited in the endnotes]. K. Panetta, "5 Trends Emerge in the Gartner Hype Cycle for Emerging Technologies”, 2017. [Online]. Available: https://www.gartner.com/smarterwithgartner/toptrends-in-the-gartner-hype-cycle-for-emerging-technologies-2017/. [Accessed: June 07, 2019].

[55] [Cited in the appendix]. K. Sandberg and M. Overgaard, "Using the perceptual awareness scale (PAS)", in Behavioral Methods in Consciousness Research, M. Overgaard, Ed., Oxford: Oxford University Press, pp. 181-196, 2015.

[56] [Cited in the appendix]. G. C. Moore and I. Benbasat, "Development of an Instrument to Measure the Perceptions of Adopting an Information Technology Innovation", Information Systems Research, vol. 2, no. 3, pp. 192-222, 1991 
i This paper refers to "Blockchain technology", because most consumers are expected to be more familiar with the commonly used term "Blockchain" than with the more broadly defined, but much more abstract concept of "distributed ledgers". Anyhow, results might also be relevant for applications based on distributed ledgers that are not built on Blockchains.

ii Referring to a survey among German consumers by Yougov Deutschland $\mathrm{GmbH}$, only $4 \%$ of consumers use the Internet to deal with cryptocurrencies like Bitcoin as the most commonly used Blockchain-based application among consumers [3]. The low percentage of users is replicated in the present study $(3.2 \%$, cf. part 5$)$.

iii Besides payments based on cryptocurrencies, consumer-oriented apps relying on $\mathrm{BCT}$ already offer a wide range of services, for example, cloud or messaging services [52].

iv This evidence, which is discussed regularly under the heading of "IntentionBehaviour-Gap", can be traced back to various causes, e.g. unexpected problems or emotions occurring in real situations that have not been anticipated when hypothetically forming an intention [13].

v Many well-known acceptance theories and models like the "Unified Theory of Adoption and Usage of Technologies" (UTAUT) or the "Technical Acceptance Model" (TAM) use intention as an acceptance variable.

vi This does not imply that these processes need to be conscious or cannot include spontaneous components or emotions [13]. Anyhow, to explain spontaneously initiated and predominantly affective decisions to perform a behaviour of interest, the theory should not be used [24].

vii Alternatively, it can be interpreted as further Behavioural Belief, addicted to the expected outcome of trying out BCT.

viii The theory specifies four more beliefs ("Relative advantage", "Compatibility", "Complexity" and "Observability") that determine overall evaluation of an innovation that show analogies to PEOU (Complexity) or PU (Relative Advantage) and have been used for investigations until today, but are not significant in all applications [34]. In consequence, only Trialability is explicitly taken into account

ix Authors discuss "Perceived customer dependence" from a sales perspective [35]. $\mathrm{x} 93.4 \%$ of the participants had a graduation qualifying for university entrance (for comparison with the German population, see [53]).

xi Reference technologies were selected comparing the "Hype Cycle for Emerging Technologies" of the consulting company "Gartner, Inc." from the years 2015 to 2017. The aim was to select emerging technologies in different stages of diffusion [54].

xii Earlier surveys focussing the Bitcoin Blockchain yield a negative correlation between age and awareness as well as between age and usage (intention) [14, 15], which can broadly be replicated by the present data ( $\mathrm{r}$ (Spearman rank coefficient) of age and awareness $=0,24, \mathrm{p}<0.05 ; \mathrm{r}$ (rank coefficient) of age and usage intention $=-0,16(\mathrm{p}<0.1))$.

xiii But interestingly eleven declare to actually own or have owned cryptocurrencies (and only four of these eleven seem to be aware of the fact that they thereby use BCT), which indicates that cryptocurrencies and BCT are not necessarily connected in consumers' perception. Because respondents were further asked to specify the cryptocurrencies they own and all stating to own some have Bitcoin or Ether as Blockchain-based cryptocurrencies in their portfolio, this can definitely not be a sophisticated statement based on the fact that not all cryptocurrencies are based on Blockchains. Anyhow, a generalisation of this incident is not possible due to the low numbers of users participating in the survey.

xiv The higher an item's weighting factor, that can be interpreted as regression coefficient [44], the more it determines the influence of the corresponding latent variable on others (and ultimately on Usage Intention).

xv The classification assumes a normal distribution based on earlier research and is not completely sharp because of "innovativeness" being a continuous variable [33]. Anyhow, it allows a rough estimation of the percentage that different Adopter Types represent in the population. 